Table 1

Current-Carrying Capacity of Copper Wire Rated at 700 C.M. Per Ampere

\begin{tabular}{cccc}
$\begin{array}{c}\text { Wire } \\
\text { Size } \\
\text { AWG }\end{array}$ & $\begin{array}{c}\text { Diameter } \\
\text { in Mils }\end{array}$ & $\begin{array}{c}\text { Circular } \\
\text { Mil Area } \\
\text { (C.M.) }\end{array}$ & $\begin{array}{c}\text { Current- } \\
\text { Carrying } \\
\text { Capacity } \\
\text { (Amperes) }\end{array}$ \\
\hline 7 & 144.3 & 20820 & 29.7 \\
8 & 128.5 & 16510 & 23.6 \\
9 & 114.4 & 13090 & 18.7 \\
10 & 101.9 & 10380 & 14.8 \\
11 & 90.7 & 8234 & 11.8 \\
12 & 80.8 & 6530 & 9.33 \\
13 & 72.0 & 5178 & 7.4 \\
14 & 64.1 & 4107 & 5.87 \\
15 & 57.1 & 3257 & 4.65 \\
16 & 50.8 & 2583 & 3.69 \\
\hline
\end{tabular}

should be used to insure that the weld itself is not subject to stress.

The conductivity of a properly made weld is essentially the same as that of the uninterrupted parent material.

NOTE

1. Ewald Instrument Corporation, Box 124, Kent, Connecticut 06757.

(Received for publication March 9, 1973; accepted March 13, 1973.)

\section{Chronic implantation of a stable jugular catheter}

\section{DOUGLAS L. CHUTE}

Department of Psychology and John M. Dalton Research Center University of Missouri, Columbia, Missouri 65201

One method of intravenous injection in the rat has been via the femoral vein or tail vein. This method may be too slow for certain experimental or pharmacological purposes. Furthermore, a good deal of dexterity is required in handling the unanesthetized animal. The alternative has been the chronically indwelling catheter. Various methods have been described, varying in cost, availability of materials, time, and effectiveness (Still \& Whitcomb, 1956; Weeks \& Davis, 1964; Weeks, 1967; Steffens, 1969). Although of superior durability, they generally are more time consuming and costly. Often the animals' freedom of movement or the experimental apparatus has to be restricted to accommodate cantilever supports for tubing.

The following technique is effective (Chute \& Wright, 1973) and offers considerable savings in expense and effort.

\section{CONSTRUCTION ANDD IMPLANTATION}

The catheter itself is a 0.050 -in. (o.d.) polyethylene tube (Intramedic R) with one end beveled and the other press-fit over the shortened shank of a 20 -ga hypodermic needle. The needle is fitted with a 3-1 cork (Fig. 1).

The surgical procedure requires about $20 \mathrm{~min}$ from the onset of anesthesia. The head and throat are shaved and prepared. A longitudinal incision is made midline in the scalp, and tissue is retracted as far as the dorso-lateral flexures by gentle periosteal elevation. The skull is prepared, and a base of dental acrylic is applied. Secure anchoring of the acrylic base is essential, and is accomplished in the usual manner with skull screws or suture wire (Draper \& Venator, 1972). The catheter is filled with a 1,000-unit solution of sodium heparin (Liquamin R), and the corked needle hub is affixed to the base with additional dental acrylic. The acrylic also is sufficient to hold the tubing and needle junction in place.

Next, a longitudinal incision is made over the right external jugular. The cannula is run subcutaneously behind the right ear, and then eventually to the incision
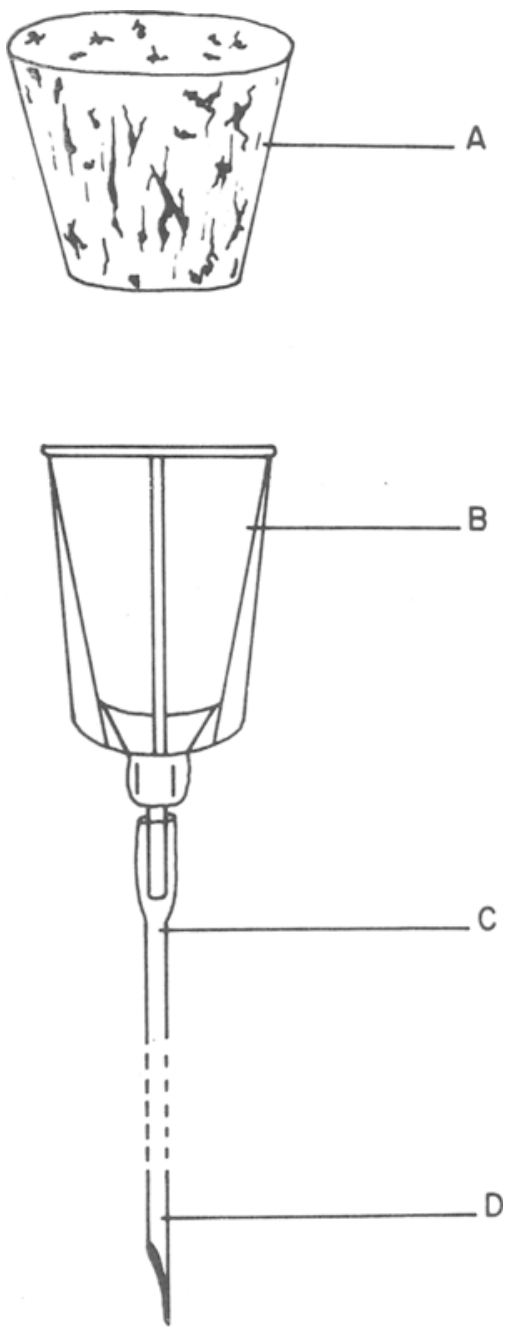

Fig. 1. Diagram of jugular catheter. Arrows indicate: (a) 3-0 cork, (b) 20-ga needle hub with shortened shank, (c) 0.050-in. o.d. polyethylene tubing, and (d) beveled end with point blunted. 


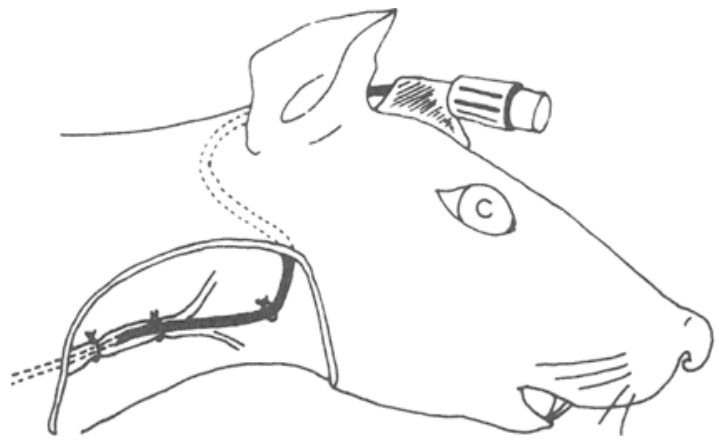

Fig. 2. Diagram of catheter placement.

in the throat. This is easily accomplished by using a convenient length of hypodermic tubing with an inside diameter large enough to accommodate the catheter. Expose about $10 \mathrm{~mm}$ of the vein, completely separating it from the surrounding tissue by blunt dissection. The jugular is ligated rostrally to the point of insertion, with the "tails" of the 3.0 suture left about $6 \mathrm{~cm}$ long. Another length of suture is placed around the vein, caudal to the point of insertion ready to be drawn tightly after the catheter is in place. The lumen of the vein is cut into on a diagonal, rostral to caudal, with iris scissors. The catheter is gently guided down the vein (about $2 \mathrm{~cm}$ ) until resistance is felt, the tip being at the junction of the superior and inferior vena cavae. If properly in place, some blood will flow back up the catheter. Draw tight the caudal suture, and, using the "tails" of suture from the rostral ligation, tie the catheter down. It is then held in the appropriate attitude following the normal course of the vein. An additional knot should be loosely tied, to avoid necrosis, binding the sternomastoideus muscle and catheter at the point of inflection. A topical antiseptic (Neosporin R) before closure and 50,000 units IM of procaine penicillin $G$ seem sufficient to control infection. Clean procedure is indicated throughout with catheters and instruments being soaked in a 1:750 tincture of benzalkonium chloride solution. Following surgery, and every day thereafter, the catheter should be flushed with $0.10 \mathrm{cc}$ of a 1,000-unit solution of Liquiamin R.

Figure 2 illustrates a catheter in place. The "S"-shaped path from head to vein is important as it seems to absorb movement and shock, thus decreasing failures.

This technique has limitations. Catheters usually are patent for only about 2 months, after which failure rate rapidly increases due to cell packing or clotting. Mature rats should be used, as growth tends to dislodge the catheter. Withdrawal of blood samples greater than $0.10 \mathrm{cc}$ is not reliable. A method of aortic cannulization has been described (Weeks, 1967), and certain features of the technique are adaptable if larger samples are required.

The advantages of this technique arise from the low cost in time and material. In addition. the animal is free of encumbrances. Injection is simple in an animal restrained only by hand, as a syringe can be easily inserted in the uncorked needle hub.

\section{REFERENCES}

Chute, D. L., \& Wright, D. C. Retrograde state dependent learning. Science, 1973, in press.

Draper, D. O., \& Venator, E. R. Chronic attachment of a connector to a rat's skull without screws. Physiology \& Behavior, 1972, 9, 113.

Steffens, A. B. A method for frequent sampling of blood and continuous infusion of fluids in the rat without disturbing the animal. Physiology \& Behavior, 1969, 4, 833-836.

Still. J. W. \& Whitcomb, E. R. Technique for permanent long-term intubation of rat aorta. Journal of Laboratory \& Clinical Medicine, 1956, 48, 152-154.

Weeks, J. R., \& Davis, J. D. Chronic intravenous cannulas for rats. Journal of A pplied Physiology, 1964, 19, 540-541.

Weeks, J. R. Cardiovascular techniques using unanesthetized and freely moving rats. Pharmacology Research, The Upjohn Company, Kalamazoo, Michigan, 1967.

(Received for publication March 9, 1973; accepted March 14, 1973.)

\section{A $1 \frac{1 / 2}{2}$ stereotactic instrument}

\author{
GUY C. SHEATZ \\ Department of Experimental Psychophysiolog. \\ Walter Reed Army Institute of Research \\ Walter Reed Army Medical Center, Washington, D.C. 20012
}

Stereotactic instruments are a means of locating specific brain areas of an organism, using a knowledge of the relationship between anatomical aspects of the animal's skull and deep structures. Characteristically, a set of coordinants of a deep structure are derived from a stereotactic atlas. These coordinants are used to position an electrode carrier precisely. Most instruments use an electrode carrier that is movable along a sequence of calibrated rails in the ventral, lateral, or anterior coordinants.

An inconvenience arises in the use of the standard stereotactic instrument for modern multielectrode implantation. It is necessary to purchase "zeroing" plates to align additional electrodes once the animal's head is fixed in the instrument. The present instrument solves this problem in another way and introduces other innovations. An example of the latter is the simple method of establishing three-dimensional coordinates. The manner in which this is ordinarily accomplished is responsible for a large part of the cost of manufacturing such instruments. The following operational outline should set these innovations in functional perspective with common stereotactic procedures.

Panel meter terminology is used to abbreviate the title. The full meaning appears with a description of the instrument having an electrode alignment matrix in addition to an implantation matrix (see Fig. 1). By lifting the spring-set plunger at $A$, the elecirode complex can be alternated between the alignment and implantation matrices, each fixed precisely by detents. B identifies the intersection of the two horizontal 